\title{
Beyond the origin
}

\author{
This issue of Nature anticipates next year's bicentenary of Charles Darwin's birth and the 150th \\ anniversary of On The Origin of Species. We begin here with a look 50 years into the future.
}

$1 /($ reation is not an event that happened in $4004 \mathrm{BC}$," the geneticist Theodosius Dobzhansky wrote in 1973. "It is a process that began some 10 billion years ago and is still under way." The realization that the processes of biological creation are at once unspeakably old, and in continuous play around us, is one of the greatest discoveries of history. And yet this discovery — unlike that unceasing and ancient creation itself — can be assigned a well-defined and comparatively recent origin in the mid-nineteenth century.

Ideas on the transmutation of forms and the evolution of life have a long history; so, indeed, do Charles Darwin's personal views on the matter, which have provided historians with grist for many mills. (For Nature's Darwin coverage in this issue, see page 295, and online at www.nature.com/darwin.) But the way in which Darwin put together evidence and argument in On the Origin of Species marked a definitive break, and an undeniable beginning. The book, 149 years old this week, provided for the first time a way of reconciling life's past and present - a way to explain both the staggering diversity of life and its fundamental unity.

That view of life has been enriched and strengthened in the intervening century and a half, and will continue to be so. But the coming decades could also see Darwin's purview expanded in fundamental ways. The discovery of the universality of the genetic code in the 1960s - the same in elephants and E. coli, as the French molecular biologist Jacques Monod famously put it - magnificently bore out Darwin's view that life is united in a common descent. But that need not remain the case.

One distinct possibility is that evidence of life beyond Earth will be found by detecting tell-tale features in the spectra of planets orbiting other stars. Although astronomers are hardly likely to be able to observe variation and evolution of that life in the next 50 years, detection alone could provide insight into the frequency of life's origination. And that, in turn, could help illuminate how life came to be

on Earth - a problem that classical Darwinism is hard put to answer.

An even more likely development is that life will be created de novo here on Earth. The first experiments in whole-organism synthetic biology, such as the synthetic mycoplasma being worked on at the J. Craig Venter Institute in Rockville, Maryland, will cleave quite closely to the designs already developed by natural selection. But there are already schemes for going further - for using different genetic codes, for example. Although the synthesis of complex organisms might remain the stuff of fantasy for some time (see page 310), new ways of building self-replicating, one-genome, one-cell organisms seem quite plausible. The development of creatures born from an idea, not an ancestor, will undoubtedly provide new insights into evolution, not least because the proclivities of such creatures to evolve will need

"Creatures born from an idea, not an ancestor, will undoubtedly provide new insights into evolution." to be kept in check.

By the time the 200th birthday of On the Origin of Species is celebrated, the life under study by science may well no longer be united by common ancestry in the way that all life is today. In that sense, Darwin's view of the world will have been superseded. But whether that life exists around another star or in a bioreactor, it will still evolve, if given leave to, according to the simple and aweinspiring algorithms of natural selection.

The essay of Dobzhansky's quoted earlier bears the now-famous title "Nothing in biology makes sense except in the light of evolution". That is so close to being an analytical truth - a necessary implication of what life itself is - that we can be certain it will continue to be true into the future. But that certainty in no way limits the diversity and sheer wonder of what we will find on the voyage that Darwin began.

\section{Call to action}

\section{European scientists who support neuroscience research on primates should tell their politicians why.}

\footnotetext{
n 1996, Giacomo Rizzolatti and his colleagues at the University of Parma in Italy published a finding that many neuroscientists regard as a landmark. By means of electrodes inserted into the inferior frontal cortex of macaque monkeys, they discovered neurons that responded not only to the monkeys' own actions but also to similar actions the subjects observed in other monkeys. There is strong suggestive evidence of similar 'mirror neurons' in humans. Such neurons, now thought to have a role in understanding
}

others' behaviour and emotions, have stimulated a great deal of fundamental research, as well as hypotheses relating to several cognitive disorders, including autism.

No grants committee could have foreseen the relevance of these fundamental primate experiments to human pathologies. That is precisely why a new directive proposed by the European Commission earlier this month requires action by anyone who thinks such research to be desirable.

The directive's intent, laudable in principle, is to introduce a new baseline of regulation of the use of animals in research across the 27 member countries of the European Union (EU). Standards of care currently vary greatly across the member states. So the draft directive would enforce on every lab a level of regulation already implemented in the countries most protective of research animals' interests. Such 